\title{
An Essential Component in Steroid Synthesis, the Steroidogenic Acute Regulatory Protein, Is Expressed in Discrete Regions of the Brain
}

\author{
Steven R. King, ${ }^{1,2,3}$ Pulak R. Manna, ${ }^{4}$ Tomohiro Ishii, ${ }^{6}$ Peter J. Syapin, ${ }^{5}$ Stephen D. Ginsberg, ${ }^{7}$ Kevin Wilson, ${ }^{4}$ \\ Lance P. Walsh, ${ }^{4}$ Keith L. Parker, ${ }^{6}$ Douglas M. Stocco, ${ }^{4}$ Roy G. Smith, ${ }^{2,3}$ and Dolores J. Lamb ${ }^{1,3}$ \\ ${ }^{1}$ Scott Department of Urology, ${ }^{2}$ Huffington Center on Aging, and ${ }^{3}$ Department of Molecular and Cellular Biology, Baylor \\ College of Medicine, Houston, Texas 77030, Departments of ${ }^{4}$ Cell Biology and Biochemistry and ${ }^{5}$ Pharmacology, Texas \\ Tech University Health Sciences Center, Lubbock, Texas 79430, ${ }^{6}$ Departments of Internal Medicine and Pharmacology, \\ University of Texas Southwestern Medical Center, Dallas, Texas 75390, and ${ }^{7}$ Center for Dementia Research, Nathan Kline \\ Institute, New York University School of Medicine, Orangeburg, New York 10962
}

Recent data implicate locally produced steroids, termed neurosteroids, as regulators of neuronal function. Adrenal and gonadal steroidogenesis is controlled by changes in the steroidogenic acute regulatory protein (StAR); however, little is known about the regulation of neurosteroid production. We now demonstrate unequivocally that StAR mRNA and protein are expressed within glia and neurons in discrete regions of the mouse brain, and that glial StAR expression is inducible. Con- sistent with a role in de novo neurosteroidogenesis, StAR colocalizes with the cholesterol side-chain cleavage enzyme $\mathrm{P}_{450}$ in both mouse and human brains. These data support a role for StAR in the production of neurosteroids and identify potential sites of active de novo steroid synthesis in the brain.

Key words: neurosteroid; steroidogenic acute regulatory pro-

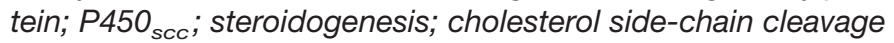
enzyme; StAR
The rate-limiting step in steroid biosynthesis is regulated by the steroidogenic acute regulatory protein (StAR) (Stocco and Clark, 1996; Stocco, 2001). StAR mediates the transfer of cholesterol from the outer to the inner mitochondrial membrane, where cholesterol is then converted by cytochrome $\mathrm{P} 450_{\text {scc }}$ to pregnenolone, the precursor for all steroids. The critical role of StAR is demonstrated in humans and mice by the observation that mutations in StAR result in congenital lipoid adrenal hyperplasia (Lin et al., 1995; Bose et al., 1996; Caron et al., 1997). Patients carrying this mutation cannot synthesize sufficient levels of adrenal and gonadal steroids and, if untreated, die shortly after birth. The essential function of StAR in steroidogenesis is established for all tissues that synthesize steroid, except for the human placenta and the brain.

The brain synthesizes neurosteroids de novo, especially within glia (Corpechot et al., 1981; Koenig et al., 1995; Zwain and Yen, 1999; Compagnone and Mellon, 2000; Tsutsui et al., 2000), but the relative roles of locally produced neuroactive steroids and those converted from circulating precursors remain to be defined. Alterations in levels of locally produced neurosteroids in the hypothalamus, hippocampus, and other regions may serve as crucial paracrine modulators of essential brain functions, including sexual drive, learning, and memory (Majewska et al., 1986;

\footnotetext{
Received June 28, 2002; revised Sept. 5, 2002; accepted Sept. 30, 2002.

This research was supported by grants from the Gilson Longenbaugh Foundation and Alzheimer's Association Grant NIRG-00-2250 (S.D.G.); by Texas Advanced Research Program Grant 010674-0013 (P.J.S.); by National Institutes of Health (NIH) Grants DK54028 (K.L.P.), NS43939 (S.D.G.), and HD17481 (D.M.S.); by the Robert A. Welch Foundation (D.M.S.); and by NIH Grant T32-DK07763 and the Lalor Foundation (S.R.K.). We thank J. C. Hutson, Y. O. Lukyanenko, J. KossDertien, C. Y. Cutler, J. T. Le, and D. Alberts for their assistance.

Correspondence should be addressed to Dr. Dolores J. Lamb, Scott Department of Urology, Room N730, Baylor College of Medicine, One Baylor Plaza, Houston, TX 77030-3498. E-mail: dlamb@www.urol.bcm.tmc.edu.

Copyright (C) 2002 Society for Neuroscience $0270-6474 / 02 / 2210613-08 \$ 15.00 / 0$
}

Genazzani et al., 1995; Frye et al., 1996; Calogero et al., 1998; Akwa et al., 2001). Deficits in neurosteroid production may contribute to a variety of disorders, including dementia, epilepsy, premenstrual syndrome, and postpartum depression (Vallee et al., 1997; Smith et al., 1998; Beyenburg et al., 1999). Consequently, it is critical that we understand the mechanism of neurosteroid biosynthesis and regulation.

In response to trophic stimulation, StAR is rapidly synthesized as a $37 \mathrm{kDa}$ preprotein. Before or during import into the mitochondria and processing to $30 \mathrm{kDa}$ forms, StAR stimulates intermembrane cholesterol transfer (Krueger and Orme-Johnson, 1983; Epstein and Orme-Johnson, 1991; Stocco and Sodeman, 1991; Clark et al., 1994; King et al., 1995). Direct evidence in support of this function was illustrated by stimulation of steroidogenesis in COS1 cells after transient coexpression of StAR and $\mathrm{P} 450_{\text {scc }}$ (Sugawara et al., 1995a). Thus, given adequate availability of reducing equivalents for the enzymatic reaction, the sole requirements for the production of steroid in a cell are the presence of $\mathrm{P} 450_{\mathrm{scc}}$ and continual de novo synthesis of StAR. Unlike $\mathrm{P} 450_{\text {scc }}$, StAR activity is acutely regulated, and thus, StAR serves as a useful protein marker for ongoing steroidogenesis.

Expression of $\mathrm{P} 450_{\mathrm{scc}}$ in the CNS has been established previously (Le Goascogne et al., 1987), proving that the brain has the capability to synthesize the steroid. However, a lack of information on StAR localization has hampered efforts to characterize steroid-producing cells and investigate the regulation of neurosteroidogenesis. Although StAR mRNA was identified recently in the brain (Furukawa et al., 1998; Wehrenberg et al., 2001), the protein was not detected. Despite an initial report suggesting expression in the hippocampus (Kimoto et al., 2001), controversy has been raised with issues of specificity of the antisera used. Therefore, we set out to establish unambiguously whether or not 
StAR is expressed in the brain and to identify potential sites of $d e$ novo neurosteroidogenesis.

\section{MATERIALS AND METHODS}

Materials. Media were obtained from Invitrogen (Grand Island, NY). We used primary antisera against amino acids $88-98$ of StAR (previously used to verify the loss of StAR in the StAR-/- mouse) (Clark et al., 1994; Caron et al., 1997), an N-terminally truncated form of StAR (N-62; kindly provided by W. L. Miller, University of San Francisco, San Francisco, CA) (Bose et al., 1999), recombinant StAR (a gift from D. B. Hales, University of Illinois, Chicago, IL) (Hales et al., 2000), and glial fibrillary acidic protein (GFAP; Sigma, St. Louis, MO), as well as amino acids $421-441$ and 509-526 of P450 ${ }_{\text {scc }}$ and monoclonal antisera against neuronal-specific nuclear protein (NeuN) and GFAP (Chemicon, Temecula, CA).

Preparation of astrocyte cultures and measurement of steroid production. Astrocyte cultures were prepared from the mesencephalon of 15- to 16-d-old Sprague-Dawley rat embryos as detailed previously (Syapin et al., 2001) and dissected with the aid of a stereomicroscope. The cells were maintained in standard glia medium (HEPES-buffered F12/DMEM plus $10 \% \mathrm{FBS}$ ) to eliminate neuronal contaminants for $9-12 \mathrm{~d}$, until stable in appearance. We further purified and expanded cultures twice by replating (1:2 splits) to obtain confluent, quiescent, tertiary cultures in $2 \%$ FBS glia medium. Cultures devoid of oligodendrocytes and microglia were used 2-14 d later. Mouse MA-10 Leydig tumor cells (kindly provided by M. Ascoli, University of Iowa, Iowa City, IA) were maintained in culture in Waymouth's medium with $15 \%$ heat-inactivated horse serum (Clark et al., 1994). Rat C6 glioma cells from the American Type Culture Collection (Manassas, VA) were grown in high glucose-containing DMEM with 5\% FBS (Syapin, 1995).

To assess steroidogenic capability, HPLC was used. Glial cultures were incubated with $\left[{ }^{3} \mathrm{H}\right]$ mevalanolactone in the absence of serum and in the presence of $20 \mu \mathrm{M}$ SU-10603 (CIBA Pharmaceutical, Summit, NJ) and 5 $\mu \mathrm{M}$ cyanoketone (Sterling-Winthrop, Rensselaer, NY), which inhibit pregnenolone metabolism. Culture medium was extracted with two volumes of water-saturated HPLC-grade ether, and the organic phase was dried under a stream of nitrogen. This material was resuspended in 100 $\mu \mathrm{l}$ of $60 \%$ methanol and chromatographed on a Cyano HPLC column (Microsorb MV, $100 \AA$, $4.6 \mathrm{~mm} \times 25 \mathrm{~cm}$; Varian Chromatography Systems, Walnut Creek, CA) using $60 \%$ methanol as the mobile phase at $0.8 \mathrm{ml} / \mathrm{min}$. The following elution profile for several reference samples (Sigma) was obtained (in min): mevalonate lactone, 4.00; pregnenolone, 9.68; testosterone, 6.64; and estradiol, 8.4. Material eluting between 9 and $10 \mathrm{~min}$ (elution time for pregnenolone) was collected and counted in $15 \mathrm{ml}$ of the scintillation mixture Scintiverse (Fisher Scientific, Fair Lawn, NJ). No other fractions except those containing radiolabeled mevalonate lactone or pregnenolone contained radioactivity, confirming that metabolism of pregnenolone had been inhibited. Using this procedure, steroid production was observed in astrocytes.

Semiquantitative reverse transcription-PCR and immunoblot analysis. Total RNA $(8-10 \mu \mathrm{g})$ was extracted from different glial cultures derived from the same litter using Trizol (Invitrogen) and was used for semiquantitative reverse transcription (RT)-PCR (Manna et al., 1999). We used primers for forward (5'-GACCTTGAAAGGCTCAGGAAGAAC-3'; bases -51 to -27 ) and reverse (5'-TAGCTGAAGATGGACAGACTTGC-3'; bases 931-908) amplification from mouse StAR cDNA, normalizing for variations in RT-PCR efficiency using forward (5'-GAAATCGCCAATGCCAACTC-3') and reverse (5'-TCTTAGACCTGCGAGCCTCA-3') primers for L19 ribosomal protein cDNA. Reverse transcription was performed using avian myeloblastosis virus reverse transcriptase (Promega, Madison, WI), and amplification was performed using Taq DNA polymerase (Promega) in the presence of $\left[\alpha-{ }^{32} \mathrm{P}\right] \mathrm{CTP}$. We used 22 cycles in the exponential phase of the PCR with a final cycle of extension at $72^{\circ} \mathrm{C}$ for $16 \mathrm{~min}$. The resultant products were separated by $1.2 \%$ agarose gel electrophoresis, and the gels were vacuumdried and exposed to film.

Equal amounts of mitochondrial protein as determined by the Bradford assay were separated by one-dimensional SDS-PAGE. Immunoblot analysis was then performed using primary antisera and horseradish peroxidase-conjugated anti-rabbit IgG (Amersham Biosciences, Piscataway, NJ) or anti-mouse IgG (Santa Cruz Biotechnology, Santa Cruz, $\mathrm{CA})$ and a Renaissance chemiluminescence kit (Perkin-Elmer, Boston, MA) (Clark et al., 1994; King et al., 1995).

Relative band intensities for RT-PCR and Western blots were quantitated (integrated optical densities) and analyzed using the Visage 2000 computer-assisted image analysis system (BioImage, Ann Arbor, MI). For RT-PCR, bands of interest were normalized to L19 ribosomal protein mRNA levels and compared with those of unstimulated cells. Statistical analyses for these results are detailed in the figure legends.

Preparation of brain tissue. We perfused, fixed, and dissected brains from terminally anesthetized male and female adult C57BL/6 or StAR $-/-$ mice of different ages. Adult animals were perfused transcardially with PBS, followed by phosphate-buffered $4 \%$ paraformaldehyde, $\mathrm{pH} 7.4$, in phosphate buffer. Brains were removed and placed into PBS. Brains were then fixed in $4 \% p$-formaldehyde for $2 \mathrm{hr}$ before incubation on consecutive nights with $12 \%$ and then $30 \%$ sucrose solutions in phosphate buffer, $\mathrm{pH} 7.4$, at $4^{\circ} \mathrm{C}$. The brains were mounted in Tissue Tek optimal cutting temperature compound (Miles Inc., Elkhart, IN) on a chuck and, after equilibration to $-20^{\circ} \mathrm{C}$ in a cryostat, $40-\mu \mathrm{m}$-thick coronal, sagittal, and horizontal sections were cut and stored at $-20^{\circ} \mathrm{C}$ in a cryoprotectant solution (30\% glycerol and 30\% ethylene glycol in $0.2 \times$ phosphate buffer).

Neutral buffered formalin (10\%) fixed nondemented human brain tissues with no pathological evidence of neurodegenerative disease were obtained from the Harvard Brain Tissue Resource Center (McLean Hospital, Belmont, MA). Forty micrometer sections were cut using a vibratome and treated with methanol and hydrogen peroxide to quench endoperoxidase activity before antibody incubation.

Immunohistochemistry and immunofluorescence. Selected sections were washed several times in TBS and then left for $1 \mathrm{hr}$ in blocking solution (0.01\% Triton X-100, $2 \%$ serum, and 0.1 m Tris/HCl, $\mathrm{pH}$ 7.4). Samples were incubated overnight at $4^{\circ} \mathrm{C}$ with primary antibody appropriately diluted in a solution of $0.005 \%$ Triton $\mathrm{X}-100,1 \%$ serum, and $0.1 \mathrm{M}$ Tris. Immunoperoxidase labeling was then performed using the Vectastain Elite ABC kit (Vector Laboratories, Burlingame, CA) according to the manufacturer's instructions. Samples were stained with $0.05 \%$ 3,3'diaminobenzidine (DAB; Sigma) or Vector SG (Vector Laboratories) in $0.01 \%$ Triton X-100 and $0.1 \mathrm{M}$ Tris mixed with $0.03 \% \mathrm{H}_{2} \mathrm{O}_{2}$ and $10 \mathrm{~mm}$ imidazole (for DAB) and then mounted on slides (Ginsberg et al., 1995, 2000).

For immunofluorescence detection, the secondary antisera used were Alexa series red 594 and green 488 dye-conjugated anti-rabbit IgG (Molecular Probes, Eugene, OR). After several washes in TBS, tissue was then mounted and coverslipped with 1:1 Vectashield with or without $4^{\prime}, 6^{\prime}$-diamidino-2-phenylindole (DAPI) stain (Vector Laboratories) as described previously (Ginsberg et al., 1995, 2000). Microscope images were taken using an Olympus Optical (Melville, NY) BX51 microscope and a Nikon (Tokyo, Japan) E800 microscope system with MetaView 5.0 software. In general, two to three male and female brains of each group were used, and experiments were repeated three times with all antisera.

\section{RESULTS}

\section{StAR expression can be induced in cultured glial cells}

Because glia represent a primary site for neurosteroidogenesis, we first investigated whether StAR is present in astrocytes isolated from rat mesencephalon and C6 glioma cells. These cell types have been demonstrated previously to synthesize steroids (Hu et al., 1987; Papadopoulos et al., 1992), and this was verified for astrocytes with HPLC (data not shown). Expression of $\mathrm{P} 450_{\text {scc }}$ was observed by immunoblot analysis of protein from isolated mitochondrial preparations (data not shown).

To investigate possible StAR expression, we stimulated these cells with forskolin or dibutyryl cAMP (dbcAMP), which increases glial neurosteroid production (Hu et al., 1987) and upregulates StAR and steroid synthesis in peripheral tissues (Stocco and Clark, 1996). Using semiquantitative RT-PCR, StAR mRNA was detected under basal conditions, and its level increased $\sim 200-300 \%$ with forskolin stimulation (Fig. 1A). Levels of StAR similarly rose $\sim 300 \%$ with dbcAMP stimulation (Fig. $1 B$ ). This increase was blocked when cells were coincubated with the protein synthesis inhibitor cycloheximide (Fig. $1 C$ ). Thus, StAR is synthesized de novo in response to stimulation by an agent that induces StAR expression in classic steroidogenic tissues, such as the gonads and adrenal gland (Stocco, 2001). Similar data were obtained with C6 glioma cells (data not shown). 
A

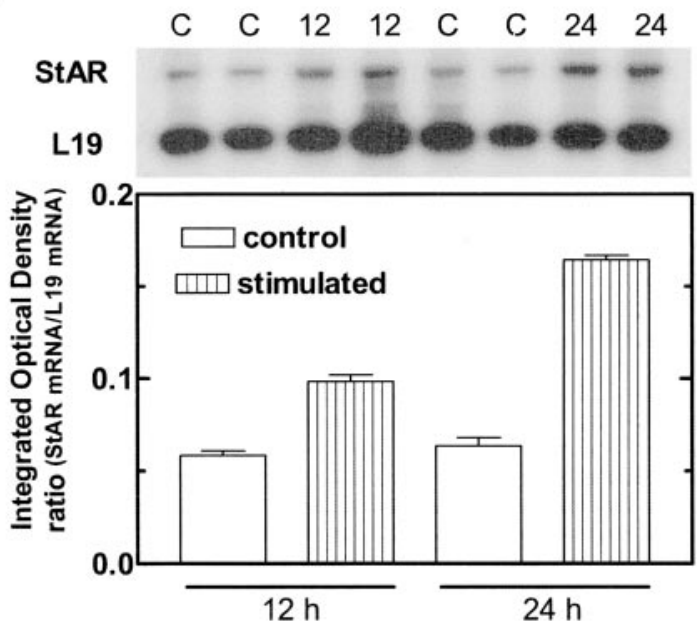

Time after stimulation

B
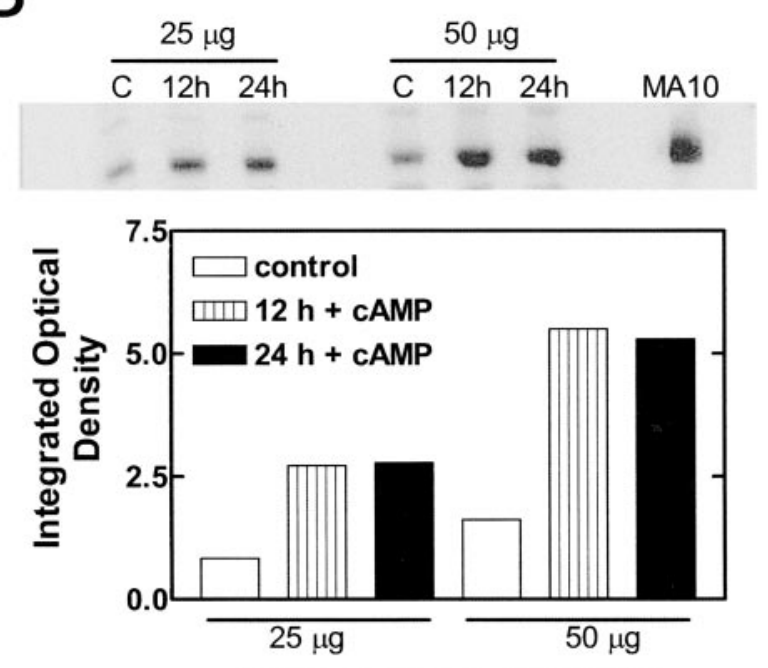

Amount of mitochondrial protein loaded

C

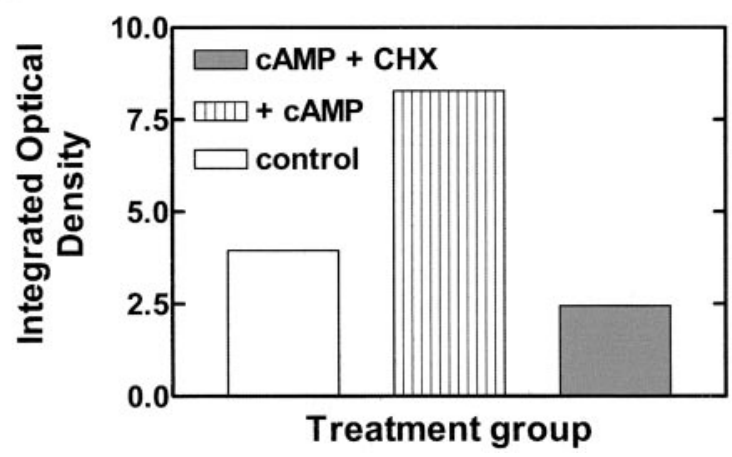

Figure 1. StAR is present in glia, and its expression is inducible by cAMP. $A$, Basal levels of StAR mRNA were detected by semiquantitative RT-PCR analysis (top, quantified in bottom). Stimulation with $40 \mu \mathrm{M}$ forskolin for 12 and $24 \mathrm{hr}$ significantly increased StAR mRNA levels by 170 and $260 \%$, respectively. Bands of interest were normalized to L19 ribosomal protein mRNA levels. Significant ratio differences between groups were determined by one-way ANOVA $(p<0.0001)$. Individual

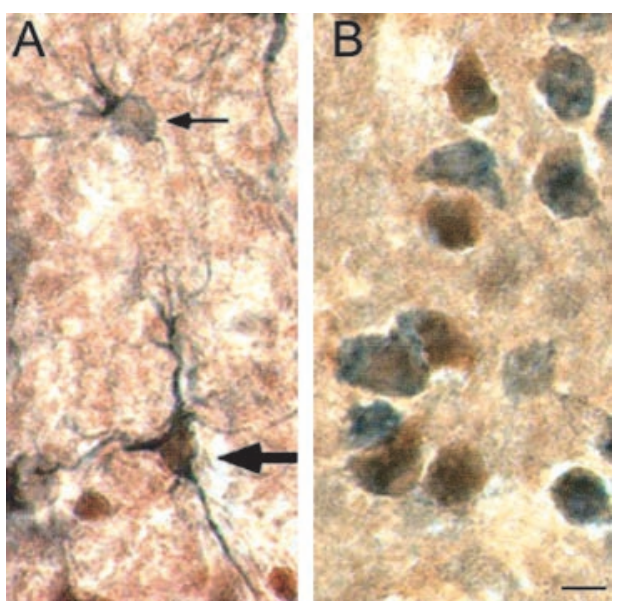

Figure 2. StAR is expressed in both glia and neurons in the brain. $A$, StAR expression in glia was demonstrated by colocalization of StAR (reddish brown) with GFAP (bluish gray) in the fimbria of the hippocampus (thick arrow). The thin arrow identifies a glial cell lacking StAR labeling. $B$, Neuronal expression of StAR was established by colocalization of StAR (reddish brown) with NeuN (bluish gray) in the striatum. Scale bar, $10 \mu \mathrm{m}$.

\section{Glial and neuronal cell populations in the brain express StAR}

Having established StAR expression in cultured glia, we surveyed various brain regions by immunohistochemistry to examine the distribution of StAR. Given the low level of glial expression and previous failures by others to detect StAR in paraffin-embedded sections (Pollack et al., 1997), a more sensitive technique was used to enhance detection using free-floating frozen sections to preserve antigenicity and increase antigen access. To ensure specificity of labeling and to rule out cross-reactivity with the StAR homolog MLN64, we used three different anti-StAR antisera, including an antipeptide antisera, and tissues from StAR-/mice, as a negative control.

Immunohistochemical analysis with each antisera yielded similar findings, with specific staining in many regions of the CNS. Expression of StAR was found in a minority of cells in the brain (likely one source of previous failures to detect StAR). All three antisera detected StAR in both neurons and glia in a similar pattern in the brain. The majority of StAR-immunopositive cells exhibited a punctate staining pattern within the somatodendritic domain, with apparent nuclear exclusion, consistent with its known mitochondrial localization. Positively stained cell types were identified by morphology and dual-labeling with antisera directed against glial and neuronal markers, GFAP and NeuN, respectively (Fig. 2). No evidence of positive immunolabeling was

$\leftarrow$

comparisons were also significant $(p<0.01)$, except between 12 and 24 hr controls $(C)$, according to the Newman-Keuls multiple comparison test. $B$, StAR levels significantly increased with $0.5 \mathrm{mg} / \mathrm{ml}$ dbcAMP stimulation by $330 \%$ and remained high over $24 \mathrm{hr}$, as revealed by immunoblot analysis (top, quantified in bottom). This relatively long time course may reflect a small population of StAR-expressing glia with high basal activity, and thus high StAR levels before stimulation. Last lane, Mitochondrial protein from positive control stimulated mouse MA-10 (MA10) Leydig tumor cells shows a strong StAR signal, confirming the identity of the glial band. The data represent an experiment performed four times with similar results. $C$, Cycloheximide $(0.5 \mu \mathrm{M})$ inhibited induction of StAR expression. Data in $A-C$ represent two separate experiments performed four times. 
Figure 3. The pons and striatum contain StAR-immunoreactive cells. $A-D$, StARimmunoreactive pontine neurons were detected using antisera generated against the $\mathrm{N}$-terminally truncated form of StAR $(A)$, amino acids $88-98$ of $\operatorname{StAR}(B)$, and recombinant StAR $(C)$, but not in StAR $-/-$ animals $(D)$. Scale bar, $50 \mu \mathrm{m}$. $E-G$, Immunopositive labeling for StAR in striatal neurons $(E)$ is in contrast to a lack of staining in same-power magnifications of the striatum from a StAR $-/-$ animal $(F)$ and striatum incubated without primary antisera $(G)$. Scale bar, 50 $\mu \mathrm{m}$.

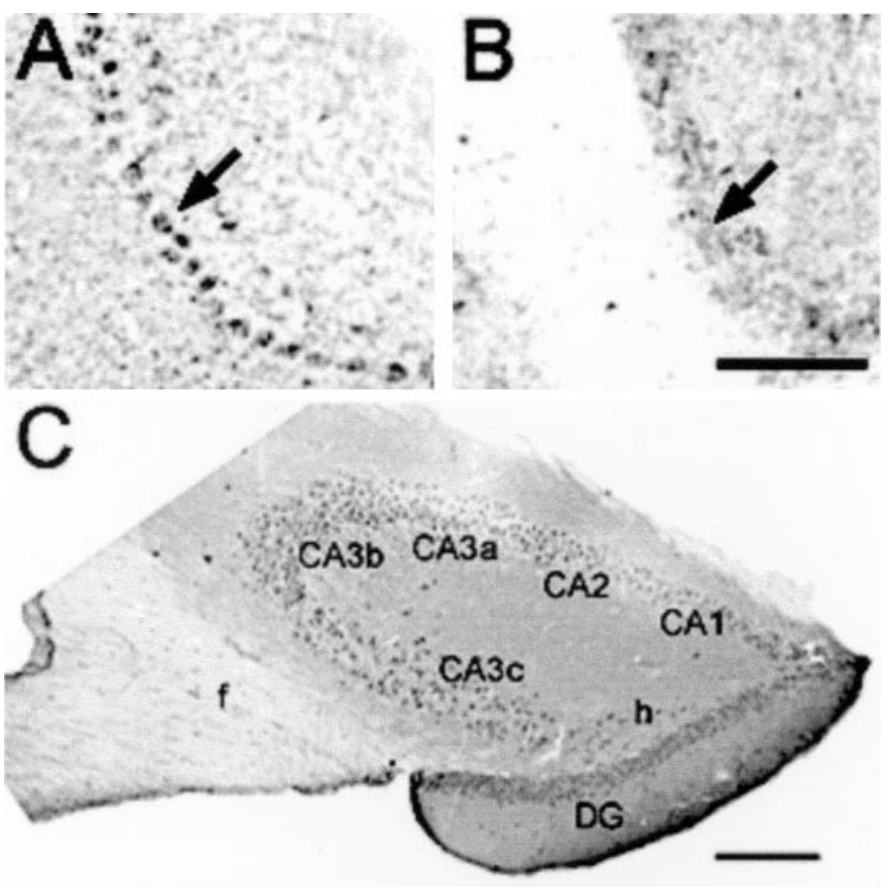

Figure 4. StAR is synthesized in the cerebellum and hippocampus. $A, B$, Intense specific staining of Purkinje cells (arrow) in the cerebellum was noted, but was absent in StAR-/- mice $(B)$. Scale bar, $50 \mu \mathrm{m}$. $C$, In the hippocampus, StAR immunoreactivity was observed in all zones of Ammon's horn (CA1-CA3) and in the dentate gyrus $(D G)$ in neurons such as hilar cells $(h)$ and in glia in the fornix $(f)$. Scale bar, $100 \mu \mathrm{m}$.

observed in tissue sections from StAR knock-out mice, which served as a negative control (Figs. $3 D, F, 4 B, 5 B$ ), or in control reactions in which the primary or secondary antisera were omitted from the reactions (Fig. $3 G$ ).

StAR was present in specific cell types in several regions of the brain, including neurons in the pons (Fig. $3 A-C$ ), medium spiny neurons of the striatum (Figs. $2 B, 3 E$ ), Purkinje cells of the cerebellum (Fig. $4 A$ ), and multiple regions of the hippocampus, including all zones of Ammon's horn (CA1-CA3), the dentate gyrus, and glial labeling within the fornix (Fig. 4C). Other regions
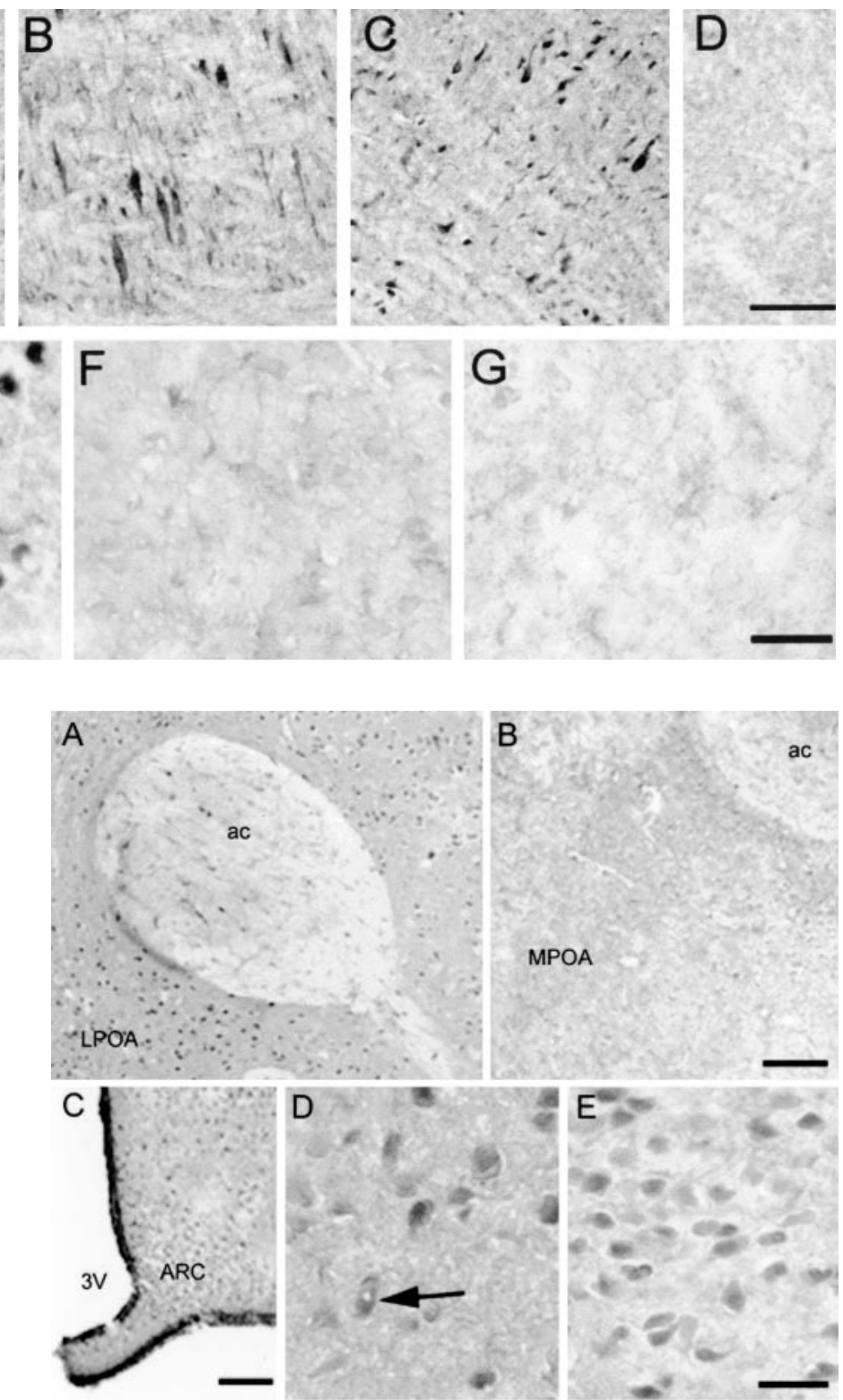

Figure 5. StAR localizes in the hypothalamus and preoptic area. $A$, StAR-containing neurons in the lateral POA $(L P O A)$ and glia in the anterior commissure $(a c)$; note in $B$ the lack of specific staining in a similar section including the medial POA (MPOA) from a StAR-/mouse. Scale bar, $50 \mu \mathrm{m}$. $C$, Low-power magnification of StAR labeling in the anterior hypothalamus including the arcuate nucleus $(A R C)$, adjacent to the third ventricle $(3 V)$. Scale bar, $100 \mu \mathrm{m}$. $D, E$, Immunopositive neurons in the medial POA and arcuate nucleus. The arrow in $D$ indicates a neuron with an apparently unstained nucleus, characteristic of mitochondrial protein labeling. Scale bar, $25 \mu \mathrm{m}$.

that expressed StAR included the neocortex, including glial populations, and specific cell types in the thalamus (data not shown).

Steroid hormones play key roles in regulating sexual behavior and reproduction, and StAR immunoreactivity was also observed in several brain regions implicated in sexual behavior. In particular, StAR-immunoreactive neurons were localized to the olfactory bulb and the hypothalamus, including the preoptic area (POA), whereas glial staining was also found in the anterior commissure (Fig. 5A). Finally, StAR-immunoreactive neurons were also found in the arcuate nucleus, a structure that is critical 


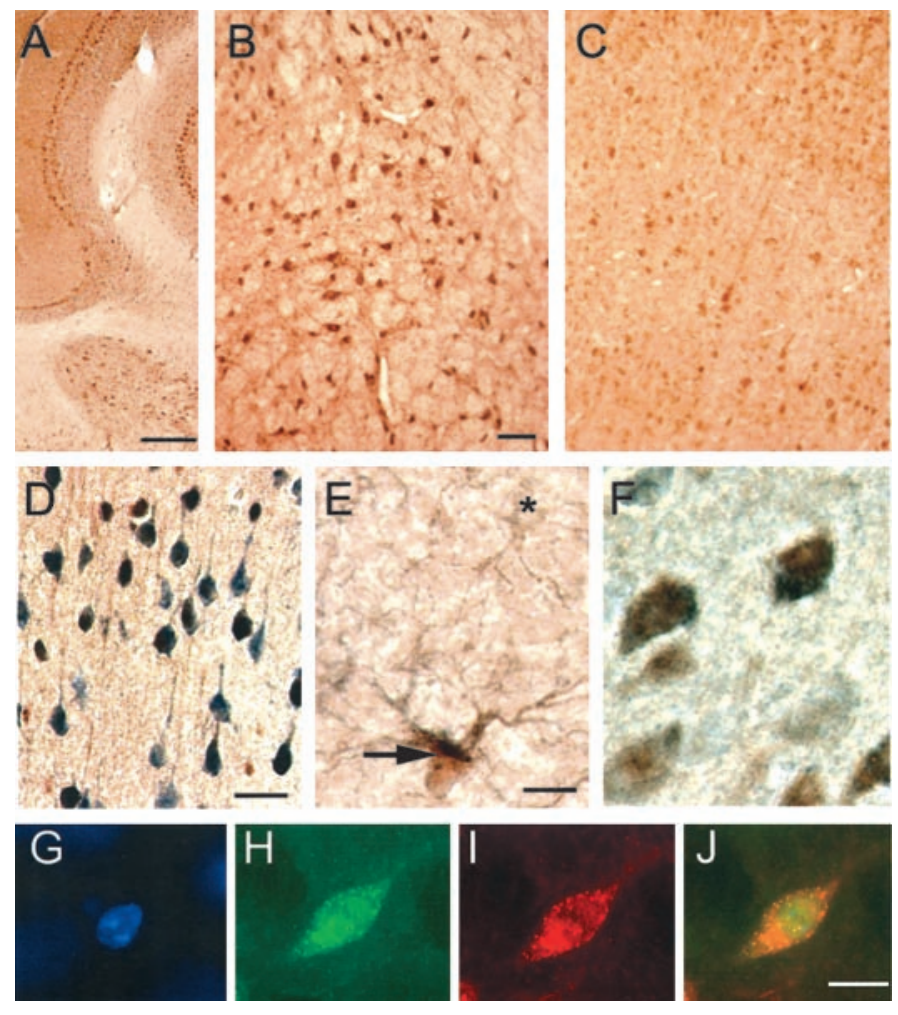

Figure 6. StAR is expressed in steroidogenic cells in the brain. $A-C$, $\mathrm{P} 450_{\text {scc }}$ immunoreactivity was detected in the cerebellum $(A)$, pons $(B)$, and cerebral cortex $(C) . D, E$, As with StAR, P450 scc $_{\text {(reddish brown) }}$ colocalized in individual cells with NeuN (bluish gray), shown in the cerebral cortex $(D)$, and GFAP, as in the lateral hypothalamus (indicated by thick arrow; cell lacking $\mathrm{P} 40_{\text {scc }}$ indicated by an asterisk, E), indicating expression in both neurons and glia. $F$, StAR (bluish gray) and $\mathrm{P} 450_{\text {scc }}$ (reddish brown) immunoreactivity colocalized in cells within the cerebral cortex. $G-J$, Nuclear-excluded immunofluorescence (by DAPI stain, $G$ ) established for StAR $(H$, red $)$ and $\mathrm{P}_{450}$ scc $(I$, green $)$ mitochondrial-type colocalization (visualized in three channels in $J$ ), using DAPI, Texas Red, and FITC filters. Scale bars: $A, 100 \mu \mathrm{m} ; B-D, 50 \mu \mathrm{m} ; E, F, G-J, 25 \mu \mathrm{m}$.

in gonadotropin-releasing hormone $(\mathrm{GnRH})$ signaling (Fig. $5 C, D)$. Collectively, the present data elucidate specific cell types within discrete brain regions that express StAR.

\section{Discrete cell populations in the brain express both StAR and $\mathbf{P 4 5 0}_{\text {scc }}$}

De novo neurosteroidogenesis also requires expression of the cholesterol side-chain cleavage enzyme $\mathrm{P} 450_{\text {scc }}$, which catalyzes the initial reaction in the steroidogenic pathway. To determine the extent to which StAR-positive cells are potentially capable of de novo steroidogenesis, we examined whether or not they express $\mathrm{P}_{450} 0_{\mathrm{scc}}$ by immunohistochemistry using two different antisera. Both antisera produced immunopositive signals localized in a manner typical of mitochondrial proteins, with punctate cytoplasmic staining and nuclear exclusion. As seen with StAR, P450 immunoreactivity was observed in multiple brain regions, including the cerebellum, pons, cerebral cortex, and hypothalamus (Fig. $6 A-E)$. As was the case for StAR, $\mathrm{P} 450_{\text {scc }}$ immunoreactivity was present in both various neuronal as well as glial populations (Fig. $6 D, E)$. Most importantly, dual-label immunohistochemical analyses revealed colocalization of StAR and $\mathrm{P} 450_{\text {scc }}$ immunoreactivities in many cells in the CNS, including cortical neurons (Fig. $6 F$ ). Using triple-label immunofluorescence, a punctate pattern of labeling was again observed with nuclear exclusion, as con-
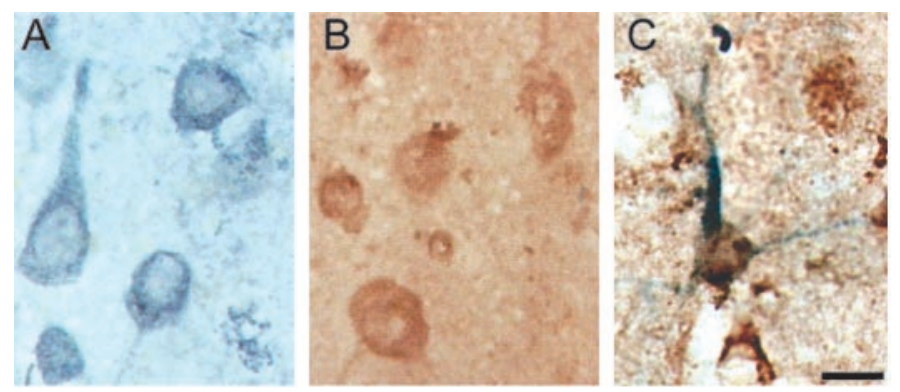

Figure 7. Cells in the human brain express both StAR and $\mathrm{P} 450_{\text {scc }} \cdot A-C$, Expression of StAR $\left(A\right.$, bluish gray) and $\mathrm{P} 450_{\text {scc }}(B$, reddish brown $)$ was observed with colocalization in various cell types including neurons in the human frontal cortex ( $C$, dual label). Scale bar, $25 \mu \mathrm{m}$.

firmed by DAPI staining, consistent with a mitochondrial colocalization (Fig. $6 G-J$ ). The coordinate expression of StAR and $\mathrm{P} 450_{\text {scc }}$ in specific cell types establishes that these cells contain both the essential mediator of cholesterol delivery and the enzyme that performs the initial reaction in the steroidogenic pathway.

\section{Both StAR and $\mathrm{P}^{450} \mathrm{scc}_{\text {sce }}$ are expressed and colocalize in the human brain}

To determine whether StAR and $\mathrm{P} 450_{\mathrm{scc}}$ protein expression could also be demonstrated in the human brain, immunohistochemical techniques were once again used. Expression and colocalization of both proteins were observed in the human CNS with an apparent mitochondrial localization (Fig. 7). These results are consistent with the data obtained with the rodent and support the conclusion that the human brain contains sites of active neurosteroid synthesis.

\section{DISCUSSION}

The local production of neurosteroids such as allopregnanolone and pregnenolone sulfate in the brain has been implicated in the regulation of many important functions, such as sexual behavior and memory. Inhibition of de novo synthesis of neurosteroids reduced dendritic spine formation in Purkinje cells in organotypic slice cultures (Sakamoto et al., 2002) and remyelination of damaged nerves by Schwann cells (Koenig et al., 1995). In addition, low hippocampal levels of pregnenolone sulfate correlate with poor performance in memory tasks by rodents (Vallee et al., 1997). Administration of neurosteroids has been proposed as a therapeutic treatment for various pathologies such as seizure disorders and memory loss attributable to aging (Akwa et al., 2001; for review, see Mellon and Griffin, 2002). Unfortunately, although such data are tantalizing, most studies of neurosteroids have been correlative or involved intracerebroventricular administration of the hormones at potentially supraphysiologic doses. Furthermore, although some data suggest the local production of many different types of neurosteroids, there have been few enzyme colocalization studies to support these observations. Thus, functions for specific steroids in different cell types have yet to be fully described. One important problem has been the lack of information regarding the mechanism by which neurosteroids are synthesized de novo. In the absence of evidence for the presence of StAR, some reports proposed a role for the ubiquitous, peripheral-type benzodiazepine receptor (PBR) (Papadopoulos et al., 1992) or the StAR homolog MLN64 (Watari 
et al., 1997), a late endosomal protein with unknown function (Moog-Lutz et al., 1997; Tsujishita and Hurley, 2000; Alpy et al., 2001). The fact remains, however, that only StAR has been unequivocally demonstrated as essential for the regulated delivery of cholesterol to the steroidogenic complex (Stocco and Clark, 1996; Stocco, 2001). The compelling evidence that StAR is a critical player in regulated steroidogenesis comes primarily from evidence provided by human subjects and knock-out mice with genetic ablation of StAR (Lin et al., 1995; Bose et al., 1996; Caron et al., 1997). Despite the presence of normal PBR, these individuals are unable to produce androgens in amounts sufficient to virilize the external genitalia, and they die because of an inability to synthesize adrenal steroids (Lin et al., 1993; Caron et al., 1997).

The present studies unambiguously establish that StAR and $\mathrm{P} 450_{\text {scc }}$ expression colocalize within discrete cells in the brain. By using immunodetection techniques with an antipeptide antisera against StAR that does not recognize MLN64 with brain sections from StAR knock-out mice, we have completely excluded the possibility that the immunohistochemical signal reflects expression of the closely related MLN64 rather than StAR.

Glia are considered the primary source of neurosteroids. Correspondingly, StAR was found in cultured rat astrocytes that contained $\mathrm{P} 450_{\mathrm{scc}}$. As in peripheral tissues, StAR expression was inducible through stimulation of the cAMP pathway. This pathway is also important in acute induction of neurosteroidogenesis ( $\mathrm{Hu}$ et al., 1987). In contrast to the results of Kimoto et al. (2001), no evidence was found for the existence of a StAR-precursor pool. Only the $30 \mathrm{kDa}$ mature protein was detected, and significantly, when cells were stimulated in the presence of cycloheximide, StAR levels did not increase. Therefore, the observed increase in StAR levels was caused by new synthesis and not by processing from existing $37 \mathrm{kDa}$ precursor proteins.

These results are important, because they reveal StAR expression in cells that are steroidogenic. The regional pattern of $\mathrm{P} 450_{\text {scc }}$ expression is similar to that reported previously for the rat (Le Goascogne et al., 1987; Iwahashi et al., 1990; Compagnone et al., 1995) and correlates with StAR expression. Moreover, P450 $0_{\text {scc }}$ and StAR immunoreactivity were colocalized to individual cells. Because synthesis of StAR directly results in increased mitochondrial intermembrane cholesterol transfer to $\mathrm{P} 450_{\mathrm{scc}}$ and hence, in steroid synthesis, it is reasonable to propose that steroidogenesis in the CNS, like that in peripheral tissues, is acutely regulated through a StAR-dependent mechanism.

It is difficult to provide a precise comparison of relative levels of StAR in the brain and peripheral steroidogenic tissues (e.g., adrenal cortex and gonads), because only a subset of cells express StAR, even in the regions that have the highest expression. Differences in the percentage of steroidogenic cells can lead to incorrect conclusions regarding the steroidogenic activity of the tissue. Nonetheless, the level of $\mathrm{P} 450_{\mathrm{scc}}$ protein in the rat brain has been estimated to be $1 \%$ of that found in mouse Y1 adrenocortical cells and MA-10 Leydig tumor cells, although $\mathrm{P} 450_{\mathrm{scc}}$ mRNA levels are at least four orders of magnitude lower than in the adrenal gland (Mellon and Deschepper, 1993; Compagnone et al., 1995; Beyenburg et al., 1999). The level of StAR mRNA in the CNS is considerably

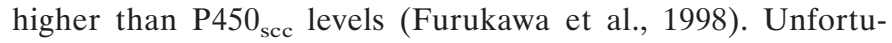
nately, it is impossible to draw a conclusion with respect to StAR levels based on mRNA data.

The present results provide compelling evidence that multiple neuronal populations are steroidogenic. Because glia are primarily described as the major steroidogenic cell type in the brain, it was unexpected that StAR and $\mathrm{P} 450_{\text {scc }}$ expression could also be localized to neuronal cell types. Although some studies have suggested that $\mathrm{P} 450_{\text {scc }}$ expression may be confined exclusively to glia (Iwahashi et al., 1990), recent publications indicate that neuronal cell types, such as Purkinje cells and neurons in the hippocampus and superior cervical ganglia, have the capacity to synthesize steroid as well (Compagnone et al., 1995; Ukena et al., 1998; Kimoto et al., 2001).

Colocalization of StAR and $\mathrm{P} 450_{\text {scc }}$ immunoreactivity allows actively steroidogenic cells in the brain to be identified. Coexpression of StAR and $\mathrm{P}_{50} 0_{\mathrm{scc}}$ in cells in various regions strongly supports the proposed roles for neurosteroids. For instance, the presence of StAR and $\mathrm{P} 450_{\mathrm{scc}}$ in anterior hypothalamic structures, including the POA, supports the possibility that StAR-mediated neurosteroidogenesis regulates $\mathrm{GnRH}$ release and the dopaminergic systems, which are essential for sexual drive and performance. Neuronal staining in the hippocampus is consistent with a role for StAR in proposed neurosteroid-modulated processes such as cognition and neuroprotection, which is important for memory. Thus, StAR may serve as a more sensitive marker for investigating changes in neurosteroidogenesis under various conditions and pathologies than current in vivo steroid assays.

The present data are also consistent with previous in situ analyses. One study provided evidence for colocalization of StAR mRNA with mRNAs for $\mathrm{P}_{450_{\text {scc }}}$ and $3 \beta$-hydroxysteroid dehydrogenase in Purkinje cells (Furukawa et al., 1998), supporting a role for locally produced progesterone in cerebellar development and function (Ukena et al., 1999; Sakamoto et al., 2002). The presence of aromatase mRNA in hippocampal cells that may contain StAR mRNA raises the possibility that neurons may synthesize de novo estrogen, which is an important factor in memory preservation (Wehrenberg et al., 2001). Future studies will determine whether neurosteroids are generally produced de novo within individual neuronal populations or whether pregnenolone synthesis and further conversion to other neurosteroids occur in separate distant or neighboring cell types, as in the ovary or testis.

The presence of StAR in all cells that express $\mathrm{P} 450_{\text {scc }}$ remains to be unambiguously confirmed. It is conceivable that cell types may exist in the brain that lack P450 scc $_{\text {and }}$ use StAR for another purpose, such as stimulating endogenous mitochondrial 26-hydroxylase activity (Sugawara et al., 1995b). Conversely, there may be cells that lack StAR and rely on StAR-independent steroidogenesis, which occurs in only one known tissue, the human placenta. More likely, cell types that contain only $\mathrm{P} 450_{\mathrm{scc}}$ may represent those that are steroidogenically quiescent and activate production of StAR and steroid in response to certain stimuli, such as neurotoxic stimulation in hippocampal neurons.

Collectively, these data are consistent with the hypothesis that StAR participates in the de novo production of neurosteroids. The broad expression profile of StAR and $\mathrm{P} 450_{\text {scc }}$ suggests that de novo steroidogenesis plays multiple roles in brain function. However, the physiologic importance of local neurosteroid production relative to neuroactive steroids converted from steroid precursors generated in peripheral sources (such as the adrenal gland) awaits the results of additional studies. An advantage of localized neurosteroid synthesis would be to allow greater selectivity for stimulation of specific neurons. Through the generation of transgenic mice with 
brain-specific knock-outs of StAR, it should be possible to dissect the relative roles of neurosteroids derived from de novo production and those arising from conversion of peripherally derived precursors. Together, these results provide insight into the locations of neurosteroid production and identify areas that could serve as targets for drug intervention and therapy.

\section{REFERENCES}

Akwa Y, Ladurelle N, Covey DF, Baulieu EE (2001) The synthetic enantiomer of pregnenolone sulfate is very active on memory in rats and mice, even more so than its physiological neurosteroid counterpart: distinct mechanisms? Proc Natl Acad Sci USA 98:14033-14037.

Alpy F, Stoeckel ME, Dierich A, Escola JM, Wendling C, Chenard MP, Vanier MT, Gruenberg J, Tomasetto C, Rio MC (2001) The steroidogenic acute regulatory protein homolog MLN64, a late endosomal cholesterol-binding protein. J Biol Chem 276:4261-4269.

Beyenburg S, Stoffel-Wagner B, Watzka M, Blümcke I, Bauer J, Schramm J, Bidlingmaier F, Elger CE (1999) Expression of cytochrome P450scc mRNA in the hippocampus of patients with temporal lobe epilepsy. NeuroReport 10:3067-3070

Bose HS, Sugawara T, Strauss III JF, Miller WL (1996) The pathophysiology and genetics of congenital lipoid adrenal hyperplasia. N Engl J Med 335:1870-1878.

Bose HS, Whittal RM, Baldwin MA, Miller WL (1999) The active form of the steroidogenic acute regulatory protein, StAR, appears to be a molten globule. Proc Natl Acad Sci USA 96:7250-7255.

Calogero AE, Palumbo MA, Bosboom AM, Burrello N, Ferrara E, Palumbo G, Petraglia F, D'Agata R (1998) The neuroactive steroid allopregnanolone suppresses hypothalamic gonadotropin-releasing hormone release through a mechanism mediated by the $\mathrm{GABA}_{\mathrm{A}}$ receptor. J Endocrinol 158:121-125.

Caron KM, Soo SC, Wetsel WC, Stocco DM, Clark BJ, Parker KL (1997) Targeted disruption of the mouse gene encoding steroidogenic acute regulatory protein provides insights into congenital lipoid adrenal hyperplasia. Proc Natl Acad Sci USA 94:11540-11545.

Clark BJ, Wells J, King SR, Stocco DM (1994) The purification, cloning, and expression of a novel luteinizing hormone-induced mitochondrial protein in MA-10 mouse Leydig tumor cells. Characterization of the steroidogenic acute regulatory protein (StAR). J Biol Chem 269:28314-28322.

Compagnone NA, Mellon SH (2000) Neurosteroids: biosynthesis and function of these novel neuromodulators. Front Neuroendocrinol 21:1-56.

Compagnone NA, Bulfone A, Rubenstein JL, Mellon SH (1995) Expression of the steroidogenic enzyme P450scc in the central and peripheral nervous systems during rodent embryogenesis. Endocrinology 136:2689-2696.

Corpechot C, Robel P, Axelson M, Sjovall J, Baulieu EE (1981) Characterization and measurement of dehydroepiandrosterone sulfate in rat brain. Proc Natl Acad Sci USA 78:4704-4707.

Epstein LF, Orme-Johnson NR (1991) Regulation of steroid hormone biosynthesis. Identification of precursors of a phosphoprotein targeted to the mitochondrion in stimulated rat adrenal cortex cells. J Biol Chem 266:19739-19745.

Frye CA, Van Keuren KR, Erskine MS (1996) Behavioral effects of $3 \alpha$-androstanediol I: modulation of sexual receptivity and promotion of GABA-stimulated chloride flux. Behav Brain Res 79:109-118.

Furukawa A, Miyatake A, Ohnishi T, Ichikawa Y (1998) Steroidogenic acute regulatory protein (StAR) transcripts constitutively expressed in the adult rat central nervous system: colocalization of StAR, cytochrome P-450SCC (CYP XIA1), and 3 $\beta$-hydroxysteroid dehydrogenase in the rat brain. J Neurochem 71:2231-2238.

Genazzani AR, Palumbo MA, de Micheroux AA, Artini PG, Criscuolo M, Ficarra G, Guo AL, Benelli A, Bertolini A, Petraglia F, Purdy RH (1995) Evidence for a role for the neurosteroid allopregnanolone in the modulation of reproductive function in female rats. Eur J Endocrinol 133:375-380.

Ginsberg SD, Price DL, Blackstone CD, Huganir RL, Martin LJ (1995) GluR3 is the major AMPA glutamate receptor of oxytocinergic magnocellular neurons and is localized at synapses. Neuroscience 65:563-575.

Ginsberg SD, Hemby SE, Lee VM-Y, Eberwine JH, Trojanowski JQ (2000) Expression profile of transcripts in Alzheimer's disease tanglebearing CA1 neurons. Ann Neurol 48:77-87.

Hales KH, Diemer T, Ginde S, Shankar BK, Roberts M, Bosmann HB, Hales DB (2000) Diametric effects of bacterial endotoxin lipopolysaccharide on adrenal and Leydig cell steroidogenic acute regulatory protein. Endocrinology 141:4000-4012.

Hu ZY, Bourreau E, Jung-Testas I, Robel P, Baulieu EE (1987) Neurosteroids: oligodendrocyte mitochondria convert cholesterol to pregnenolone. Proc Natl Acad Sci USA 84:8215-8219.
Iwahashi K, Ozaki HS, Tsubaki M, Ohnishi J, Takeuchi Y, Ichikawa Y (1990) Studies of the immunohistochemical and biochemical localization of the cytochrome P-450scc-linked monooxygenase system in the adult rat brain. Biochim Biophys Acta 1035:182-189.

Kimoto T, Tsurugizawa T, Ohta Y, Makino J, Tamura H, Hojo Y, Takata N, Kawato S (2001) Neurosteroid synthesis by cytochrome p450containing systems localized in the rat brain hippocampal neurons: $N$-methyl-D-aspartate and calcium-dependent synthesis. Endocrinology 142:3578-3589.

King SR, Ronen-Fuhrmann T, Timberg R, Clark BJ, Orly J, Stocco DM (1995) Steroid production after in vitro transcription, translation, and mitochondrial processing of protein products of complementary deoxyribonucleic acid for steroidogenic acute regulatory protein. Endocrinology 136:5165-5176.

Koenig HL, Schumacher M, Ferzaz B, Thi AN, Ressouches A, Guennoun R, Jung-Testas I, Robel P, Akwa Y, Baulieu EE (1995) Progesterone synthesis and myelin formation by Schwann cells. Science 268:1500-1503.

Krueger RJ, Orme-Johnson NR (1983) Acute adrenocorticotropic hormone stimulation of adrenal corticosteroidogenesis. Discovery of a rapidly induced protein. J Biol Chem 258:10159-10167.

Le Goascogne C, Robel P, Gouezou M, Sananes N, Baulieu EE, Waterman M (1987) Neurosteroids: cytochrome P-450scc in rat brain. Science 237:1212-1215.

Lin D, Chang YJ, Strauss III JF, Miller WL (1993) The human peripheral benzodiazepine receptor gene: cloning and characterization of alternative splicing in normal tissues and in a patient with congenital lipoid adrenal hyperplasia. Genomics 18:643-650.

Lin D, Sugawara T, Strauss III JF, Clark BJ, Stocco DM, Saenger P, Rogol A, Miller WL (1995) Role of steroidogenic acute regulatory protein in adrenal and gonadal steroidogenesis. Science 267:1828-1831.

Majewska MD, Harrison NL, Schwartz RD, Barker JL, Paul SM (1986) Steroid hormone metabolites are barbiturate-like modulators of the GABA receptor. Science 232:1004-1007.

Manna PR, Tena-Sempere M, Huhtaniemi IT (1999) Molecular mechanisms of thyroid hormone-stimulated steroidogenesis in mouse Leydig tumor cells. Involvement of the steroidogenic acute regulatory (StAR) protein. J Biol Chem 274:5909-5918.

Mellon SH, Deschepper CF (1993) Neurosteroid biosynthesis: genes for adrenal steroidogenic enzymes are expressed in the brain. Brain Res 629:283-292.

Mellon SH, Griffin LD (2002) Neurosteroids: biochemistry and clinical significance. Trends Endocrinol Metab 13:35-43.

Moog-Lutz C, Tomasetto C, Regnier CH, Wendling C, Lutz Y, Muller D, Chenard MP, Basset P, Rio MC (1997) MLN64 exhibits homology with the steroidogenic acute regulatory protein (StAR) and is over-expressed in human breast carcinomas. Int $\mathrm{J}$ Cancer 71:183-191.

Papadopoulos V, Guarneri P, Kreuger KE, Guidotti A, Costa E (1992) Pregnenolone biosynthesis in C6-2B glioma cell mitochondria: regulation by a mitochondrial diazepam binding inhibitor receptor. Proc Natl Acad Sci USA 89:5113-5117.

Pollack SE, Furth EE, Kallen CB, Arakane F, Kiriakidou M, Kozarsky KF, Strauss III JF (1997) Localization of the steroidogenic acute regulatory protein in human tissues. J Clin Endocrinol Metab 82:4243-4251.

Sakamoto H, Ukena K, Tsutsui K (2002) Dendritic spine formation in response to progesterone synthesized de novo in the developing Purkinje cell in rats. Neurosci Lett 322:111-115.

Smith SS, Gong QH, Hsu FC, Markowitz RS, ffrench-Mullen JM, Li X (1998) $\mathrm{GABA}_{\mathrm{A}}$ receptor $\alpha 4$ subunit suppression prevents withdrawal properties of an endogenous steroid. Nature 392:926-930.

Stocco DM (2001) Tracking the role of a star in the sky of the new millennium. Mol Endocrinol 15:1245-1254.

Stocco DM, Clark BJ (1996) Regulation of the acute production of steroids in steroidogenic cells. Endocr Rev 17:221-244.

Stocco DM, Sodeman TC (1991) The 30-kDa mitochondrial proteins induced by hormone stimulation in MA-10 mouse Leydig tumor cells are processed from larger precursors. J Biol Chem 266:19731-19738.

Sugawara T, Holt JA, Driscoll D, Strauss III JF, Lin D, Miller WL, Patterson D, Clancy KP, Hart IM, Clark BJ, Stocco DM (1995a) Human steriodogenic acute regulatory protein: functional activity in COS-1 cells, tissue-specific expression, and mapping of the structural gene to $8 \mathrm{p} 112$, a pseudogene to chromosome 13. Proc Natl Acad Sci USA 92:4778-4782.

Sugawara T, Lin D, Holt JA, Martin KO, Javitt NB, Miller WL, Strauss III JF (1995b) Structure of the human steroidogenic acute regulatory protein (StAR) gene: StAR stimulates mitochondrial cholesterol 27hydroxylase activity. Biochemistry 34:12506-12512.

Syapin PJ (1995) Ethanol inhibition of inducible nitric oxide synthase activity in C6 glioma cells. Alcohol Clin Exp Res 19:262-267. 
Syapin PJ, Koss JS, Cutler CY (2001) Inducible nitric oxide synthase expression in mesencephalic astrocyte cultures. Proc West Pharmacol Soc 44:117-119.

Tsujishita Y, Hurley JH (2000) Structure lipid transport mechanism of a StAR-related domain. Nat Struct Biol 7:408-414.

Tsutsui K, Ukena K, Usui M, Sakamoto H, Takase M (2000) Novel brain function: biosynthesis and actions of neurosteroids in neurons. Neurosci Res 36:261-273.

Ukena K, Usui M, Kohchi C, Tsutsui K (1998) Cytochrome P450 sidechain cleavage enzyme in the cerebellar Purkinje neuron and its neonatal change in rats. Endocrinology 139:137-147.

Ukena K, Kohchi C, Tsutsui K (1999) Expression and activity of $3 \beta$ hydroxysteroid dehydrogenase $/ \Delta^{5}-\Delta^{4}$-isomerase in the rat Purkinje neuron during neonatal life. Endocrinology 140:805-813.

Vallee M, Mayo W, Darnaudery M, Corpechot C, Young J, Koehl M, Le
Moal M, Baulieu EE, Robel P, Simon H (1997) Neurosteroids: deficient cognitive performance in aged rats depends on low pregnenolone sulfate levels in the hippocampus. Proc Natl Acad Sci USA 94:14865-14870.

Watari H, Arakane F, Moog-Lutz C, Kallen CB, Tomasetto C, Gerton GL, Rio MC, Baker ME, Strauss III JF (1997) MLN64 contains a domain with homology to the steroidogenic acute regulatory protein (StAR) that stimulates steroidogenesis. Proc Natl Acad Sci USA 94:8462-8467.

Wehrenberg U, Prange-Kiel J, Rune GM (2001) Steroidogenic factor-1 expression in marmoset rat hippocampus: co-localization with StAR and aromatase. J Neurochem 76:1879-1886.

Zwain IH, Yen SS (1999) Neurosteroidogenesis in astrocytes, oligodendrocytes, and neurons of cerebral cortex of rat brain. Endocrinology 140:3843-3852. 